\title{
Desirability Optimization Models to Create the Global Healthcare Competitiveness Index
}

\author{
Nergis Feride Kaplan Dönmez ${ }^{1}$ (i) $\cdot$ Abdulkadir Atalan² ${ }^{2} \cdot$ Cem Çağrı Dönmez ${ }^{3}$ (])
}

Received: 3 January 2020 / Accepted: 14 June 2020 / Published online: 24 June 2020

(c) King Fahd University of Petroleum \& Minerals 2020

\begin{abstract}
The aim of this research is to enhance desirability optimization models to create a global healthcare competitiveness index (GHCI) covering 53 countries with gross domestic product per capita (GDP PC) of over $\$ 10,000$. The GHCI is defined as an index that reveals the progress and quality of the healthcare systems in countries providing their patients with easier access opportunities to healthcare services within the scope of this work. Methods of statistical analysis have been adopted together with optimization models and techniques in this research. The optimum and feasible values of the factors considered influential on objective functions have been determined as the basis of healthcare expenditure (HE) and GHCI in those relevant countries. Those released optimum outcomes are displayed between 0.64 and 0.66 in terms of desirability value. The GHCI values of those aforementioned countries range from 0 to 6 . The computed average of the GHCI values of those countries is estimated as 2.4758 . Finally, GHCI values of 53 countries have been calculated to set the current basis of desirability optimization models. These findings will be deemed as the basic essence of those prospective theories to be established for the future researches to constitute a new index to measure the competitiveness of healthcare systems in various countries all over the world.
\end{abstract}

Keywords Desirability optimization models $\cdot$ Global healthcare competitiveness index $\cdot$ Healthcare systems $\cdot$ Healthcare expenditure

\section{Introduction}

The perspective toward the importance of the healthcare has already changed considerably in time. Globally, healthcare is accepted as the second largest sector after manufacturing businesses in terms of economy. This situation has triggered the development and growth of the healthcare sector [1]. A competitive atmosphere is created for patients to receive faster and easier health services by means of healthcare institutions. Accordingly, as the level of welfare of people increases, they demand higher quality of healthcare services

Abdulkadir Atalan

abdulkadiratalan@gmail.com

1 The Faculty of Economics, Marmara University, Istanbul 34722, Turkey

2 Faculty of Engineering and Natural Sciences, Gaziantep Islam, Science and Technology University, Gaziantep 27010 , Turkey

3 Engineering Faculty, Marmara University, Istanbul 34722, Turkey from hospitals. All of these are particularly inspiring investors to promote quality assurance in healthcare systems of countries [2]. It is desirable for people to have high patient satisfaction by receiving high-quality services conveniently at healthcare institutions. Especially, in European countries, people travel to other cities or countries because of poorquality healthcare services in the city where the patients are located. With the emergence of such a situation, many researches have been conducted to provide an easy, fast, and inexpensive healthcare service for patients [3, 4]. Factors that enable patients to have an access to healthcare have been taken into consideration in such studies, but these studies have been performed for local situations rather than general conditions. In this study, a general view is presented considering the factors that form the infrastructure of the health systems of countries.

A study measuring health system performance covering 191 countries was conducted by the World Health Organization (WHO) in 2000. Five main factors defined as health, health inequality, responsiveness-level, responsiveness-distribution, and fair-financing were determined, and 
regression equations were formed in this study. The correlation between these factors and health system performance was emphasized. These factors were limited to $[0,1]$, and a weighted value was given for each factor. Thus, the overall efficiency calculation was made in all WHO member countries, and their health systems were listed. However, this study does not include any factors regarding the economic data and health infrastructures of countries. We would like to emphasize that it would not be appropriate to make a comparison between the study conducted by WHO and our study. Because of the fact that the parameters discussed were different and that approximately 18 years had elapsed, there was no consistent comparison.

Many methods have been developed in terms of both engineering and management to solve health problems. Especially, management approaches have been widely applied in the field of healthcare [5-7]. Addressing managerial implications for the provision of medical devices [8], increasing the types of services, providing improved management information systems [9], employing skilled managers in their fields, patient case management, health quality assurance systems, and so on are important on behalf of the managers in determining the applicable strategies by taking into consideration in the field of healthcare management. Thus, the effects of healthcare problems are finally concluded with implications by the research conducted by healthcare managers [10]. However, since healthcare problems are very specific issues or unique problems, such as avoiding vital harm to patients, insufficient resources, poor healthcare services, and medication error, researchers have adopted algorithms and optimization models in order to solve these issues [11]. Therefore, optimization techniques are indispensable methods of management, engineering, and business applications.

The purpose of using optimization, also named as operation research (OR), is to provide maximum benefits (such as revenue and production) and minimize loss (such as costs, expenditure, defects, and waiting time). Optimization applications vary widely according to the areas where they are used, such as energy, automotive, manufacturing, transportation, and logistic. Optimization techniques have been exploited to solve problems in healthcare systems, which are among the most trend topics of recent years [12]. Commonly, optimization models have been developed to optimize the schedule of resources of the healthcare systems. In addition, optimization models have been established for the management of healthcare materials for logistics [13], for emergency services, to reduce waiting time for patients and to reduce expenditure or cost of treatment on healthcare facilities [14]. However, these methods have been used limitedly in the field of healthcare. The reason for this is that work or patient flows have a stochastic structure rather than a deterministic structure in the healthcare systems. Stochastic constructions are usually explained by nonlinear equations, which means the analysis of mathematical modeling is both difficult and long-lasting in parabolic situations.

Statistical analysis is an alternative method for solving healthcare problems [2]. In particular, statistical methods have been used to make predictions for management of the healthcare system in the future based on past data and experience. Especially, regression analysis was most widely used among statistical methods by researchers [15]. For this reason, regression analyses are considered as a good forecasting tool for the future. Nevertheless, this tool is not sufficient to use solutions alone in healthcare area, because of the fact that the statistical analysis obtained provides only information about what the current system will achieve in the future, not the future goals of these systems. Consequently, statistical analysis was used together with optimization technique in this study. In addition to statistical analysis, calculation of GHCI values belonging to countries was provided by using desirability optimization technique. Formulations were obtained by considering the lower and upper limits of the factors' values considered on the basis of this method. Besides, it was possible to clearly show the traces of the factors on which they affect the response that was the objective function of the optimization model with the developed methodology.

The problem statement which is an optimization model with the help of statistical analysis was developed to create GHCI to measure the structural and economic status of healthcare of considered countries in this research. While the economic development of the countries has been measured with the global competitiveness index (GCI) studies so far, in this study, we wanted to examine the development levels of the healthcare systems of the countries by creating a GHCI [16]. Up till now, the quality of healthcare has only been determined on the basis of patient satisfaction [17]. This criterion was measured according to questionnaire surveys, so the numerical data and analysis were disregarded in the studies [18]. Patient satisfaction and employee performance were measured using questionnaire or verbal interview method to determine the quality of healthcare [19]. However, it is obvious that the results of such methods are weak in terms of accuracy or not enough to reflect the real problems of healthcare. For this reason, different methods have to be used to obtain the quantitative and tangible results. Through this research, the results of the analysis with the numerical data by quality tools have led to touchable solutions for quality of the healthcare and allowed the detection of the future problems [20]. We believe that this study will be a good source for future studies in terms of the measuring method of the healthcare quality. Also, this study will have significance in theory as it promotes a new index to measure the competitiveness of healthcare system across different countries. 
This study has come to fruition in four parts. In the first section, the studies in the literature have been discussed. The methodology of the study was considered in the second section. The factors affecting the healthcare systems were determined, and methodologies of the study were constructed on this part. The statistical, optimum, and feasible results were obtained with the developed method for GHCI, and the GHCI values belonging to the countries were calculated and ranked in the third section of the study. In the last section, conclusion about the study has been provided.

\section{Methodology}

The method used in the study consists of two parts as statistical phase and optimization phase. GHCI values of the countries considered were calculated by developing nonlinear optimization models based on statistical optimization technique. As shown by the flowchart in Fig. 1, there are eight key steps as definition of inputs as decision variables, historical data collection, obtaining descriptive statistical information about the collected data and removing decision variables that are not statistically significant, determining the limits of decision variables, the decision variables and objective functions, creating the optimization models, and succeeding the optimum results for decision variables and objective functions in order to create GHCI of the countries considered.

In the statistical analysis stage, the statistical significance of the factors was analyzed to define the decision variables and the limits of these variables in the statistical analysis stage. Optimization models containing decision variables that have an impact on the objective functions were developed, and optimum values of decision variables and objective functions were obtained in the optimization stage. Finally, after calculating GHCI optimization values not included in the flowchart, an index was created to list the healthcare systems of the countries considered in this study.

\subsection{Dependent and Independent Variables}

The resources of the healthcare system of the countries were calculated by the World Bank database as the number of beds, doctors, and nurses and midwives per 1000 persons. However, for the analysis of these data to be consistent, the total number of these sources was calculated as below:

$x_{i j}=\frac{\operatorname{total} x_{i j}}{1000}$

where $x_{i j}$ is defined as a decision variable and $i$ denotes the resources of healthcare of the countries and $j$ represents the names of the countries. In this equation, $i$ only symbolizes the number of beds, doctors, and nurses and midwives per

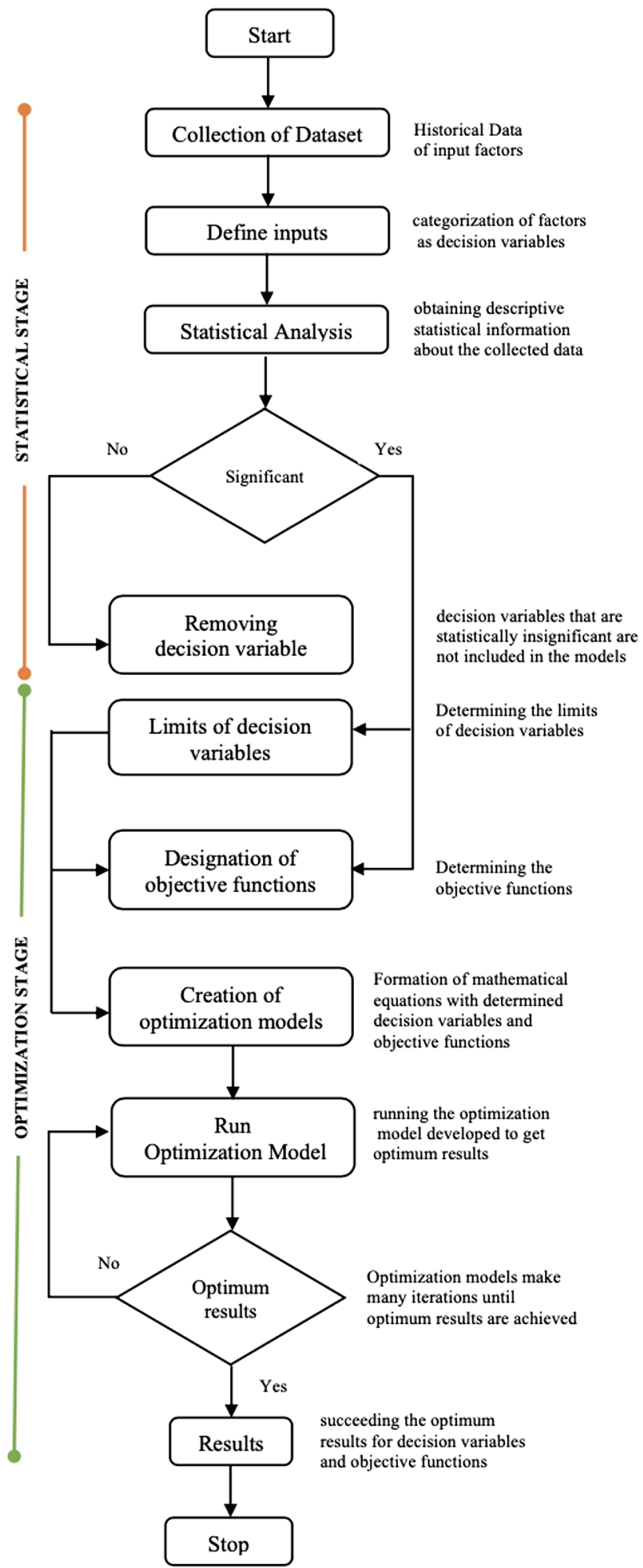

Fig. 1 Flowchart of nonlinear statistical optimization models

1000 persons, but since there are more than one factor in the study, $i$ notation representing the factors was used in general terms. Likewise, $j$ notation expresses generally the 
names of the countries considered in the study rather than writing them separately. A total $-x_{i j}$ refers to the total number of factors $i$ for beds, doctors, and nurses and midwives in country $j$.

The factors affecting healthcare systems were evaluated in two parts that were defined as structural and economical. The factors come from the resources that build the substructure of the healthcare system in the first part. The most important assessment for measuring the performance of a country's healthcare system is the relationship between resources and outcomes [21]. Some of these factors are doctors, assistant doctors, nurses, officers, patient rooms, beds, triage rooms, laboratories fulfillments of clinical requirements, general behavior of doctors, registration and administrative procedures, infrastructure and amenities, professional performance of doctors, and facilities at reception and outpatient department area [17]. These resources must be supplied and managed properly in a healthcare system. Nevertheless, deficiencies in the management of these resources are affecting the quality of healthcare in the negative direction [22]. Generally believed, physicians, nurses, and beds construct the infrastructure of the healthcare systems [23]. Thus, the numbers of physicians, nurses, and beds [24] that were used in this study were the most employed parameters in the researches [25]. We evaluated the effects of each resource on the different levels on OF the outcomes and analyzed healthcare resources individually.

The life expectancy [26] factor discussed was also considered among the structural factors in this study. Especially, this factor may be more effective in state and private healthcare systems. As a result of the previous studies, there was a strong connection between HEs and life expectancy [21]. The main reason for this deal was that people with high levels of prosperity are increasing their HEs because people want to live longer. In this case, states or private enterprises need to increase their HEs.

In terms of economy, there are many factors that are influential in the healthcare system level headedly. There are two economic factors that are gross domestic product (GDP) and gross domestic product per capita (GDP PC) of the countries considered to be influential on the healthcare systems. Countries with GDP PC of ten thousand dollars or more were regarded in this study. Moreover, in the studies carried out in terms of the relation between healthcare and income level, a positive correlation appears to exist between the income per capita and life expectancy [27].

HEs were considered as responses or dependent factors/ variables influenced by the independent factors. Most of studies covered at most six and few independent factors in the calculation of index scores. Generally, scientists suggested that the four independent variables, such as the number of physicians, nurses, beds, and healthcare expenditure per capita, were effective and reliable on the healthcare systems of countries. HE data of countries [28] were calculated by the percentages of countries dependent on GDP [29]. A statistical analysis of how these factors affect HE has been shown as the result. HEs of countries were considered as response variables. It was seen that HEs in economically developed countries are higher than those in developing countries. As a result of the statistical optimization analysis, the six important factors of which were gross domestic product, gross domestic product per capita, life expectancy, the number of beds, the number of nurses and midwives, and the number of physicians considered were more influential on HEs as revealed in this study.

\subsection{Development of Desirability Optimization Models}

Optimization models were developed with the help of mathematical equations of the developed desirability functions. Developed mathematical models are provided to minimize the amount of HEs besides of maximization of GHCI with objective function. The desirability analysis and optimization techniques have been merged to create the main methodology of this study. The desirability equations obtained as a result of statistical analysis and the GHCI values belonging to the countries were calculated to construct the optimization models. Contemplating types of factors among the countries with index $i$ and $j$ all notations are presented in Table 1 .

In the optimization model developed when decision variables are created for each country or each factor, there were 318 decision variables generated in total. Likewise, a total of 319 constraints were created by considering the lower and upper limits of each factor, in addition to contemplating the nonnegative constraint in the optimization model. The method of desirability has been developed to obtain the best results for multiple reactions or factors acting as a process. (This method is widely used for multi-objective optimization models.) It produces the best response values of the factors to minimize, maximize, or reach the target value of the specifications. While statistical analysis gives mostly linear regression equations, the equilibrium found due to the weighted factor values in the desirability technique has a nonlinear characteristic.

Before constructing the optimization models, it is necessary to consider the function of desirability according to the results to be obtained as a result of statistical analysis. The factors affecting the response function directly influence the desirability function [30]. In short, it is desirable that the factors affecting the main response values are at the target values which are measured by the value of desirability. The best result is gained as this value goes from zero to one.

The complete desirability function includes the upper and lower bound values of the factors that have an effect on the responses. GHCI was created separately for each 
Table 1 Descriptions of the optimization model's rudiments

\begin{tabular}{|c|c|c|c|}
\hline Types & Notations & Definitions & Boundaries \\
\hline Decision variables & $x_{i j}^{y}$ & The values of the types of factor $i$, the country of $j$ during the year $y$ & $\begin{array}{l}i=\{g d p, g d p p c, l e, b, m d, n w\} \\
j=\{\text { Norway }, \ldots, \text { Costa Rica }\}\end{array}$ \\
\hline \multirow[t]{4}{*}{ Parameters } & $l_{i j}^{y}$ & The lower bounds factor $i$ the country of $j$ during the year $y$ & $\forall_{y} \in{ }^{\prime} \Omega$ \\
\hline & $u_{i j}^{y}$ & The upper bounds factor $i$ the country of $j$ during the year $y$ & $\forall_{y} \in{ }^{\prime} \Omega$ \\
\hline & $\beta_{i}$ & Normalization multiplier for factor $i$ & $i=\{g d p, g d p p c, l e, b, m d, n w\}$ \\
\hline & $n_{y}$ & Total number of years & $\forall_{y} \in{ }^{\prime} \Omega$ \\
\hline \multirow[t]{2}{*}{ Objective functions } & $\sum_{i, j} \sum_{y} \mathrm{GHCI}_{i j}^{y}$ & GHCI for factor $i$ the country of $j$ in the year $y$ & $\forall_{y} \in{ }^{\prime} \Omega$ \\
\hline & $\sum_{i, j} \sum_{y} \mathrm{HE}_{i j}^{y}$ & Healthcare Expenditure for factor $i$ the country of $j$ in the year $y$ & $\forall_{y} \in{ }^{\prime} \Omega$ \\
\hline
\end{tabular}

factor. GHCI formula was obtained by geometric mean of these factors. However, the values of GHCI and HE are converted into the following formula in order to get a meaningful and accurate result. Thus, the value of GHCI and $\mathrm{HE}$ was placed between 0 and 1 .

$D^{*}=\left[1-\left(d_{1} * d_{2} * d_{3} * \ldots * d_{n}\right)^{1 / n}\right]$

where $D^{*}$ denotes the geometric mean of the desirability indexes of the factors. $d_{1}, d_{2}, d_{3}, \ldots, d_{n}$ take a value between 0 and 1. If $d_{1}=1, d_{2}=1, d_{3}=1, \ldots, d_{n}=1$, this is the desired best value, but if $d_{1}=0, d_{2}=0, d_{3}=0, \ldots, d_{n}=0$, it is the worst and undesirable value. $n$ indicates the number of factors and since there are six factors in this study, $n=6$ is written. There were six different factors in this research, and the expansion of these factors on the desirability formulas as objective functions for the optimization models was shown as below:

$$
\begin{aligned}
\operatorname{GHCI}_{i}= & {\left[\left(\frac{y_{1}-l_{1}}{u_{1}-l_{1}}\right)^{w_{1}} *\left(\frac{y_{2}-l_{2}}{u_{2}-l_{2}}\right)^{w_{2}} *\left(\frac{y_{3}-l_{3}}{u_{3}-l_{3}}\right)^{w_{3}} *\left(\frac{y_{4}-l_{4}}{u_{4}-l_{4}}\right)^{w_{4}} *\right.} \\
& \left.\left(\frac{y_{5}-l_{5}}{u_{5}-l_{5}}\right)^{w_{5}} *\left(\frac{y_{6}-l_{6}}{u_{6}-l_{6}}\right)^{w_{6}}\right]^{\frac{1}{6}} * c
\end{aligned}
$$

$$
\begin{aligned}
\mathrm{HE}_{i}= & {\left[\left(\frac{u_{1}-y_{1}}{u_{1}-l_{1}}\right)^{w_{1}} *\left(\frac{u_{2}-y_{2}}{u_{2}-l_{2}}\right)^{w_{1}} *\left(\frac{u_{3}-y_{3}}{u_{3}-l_{3}}\right)^{w_{3}} *\left(\frac{u_{4}-y_{4}}{u_{4}-l_{4}}\right)^{w_{4}} *\right.} \\
& \left.*\left(\frac{u_{5}-y_{5}}{u_{5}-l_{5}}\right)^{w_{5}} *\left(\frac{u_{6}-y_{6}}{u_{6}-l_{6}}\right)^{w_{6}}\right]^{\frac{1}{6}} * c
\end{aligned}
$$

where $l_{1}, l_{2}, l_{3}, \ldots, l_{6}$ and $l_{1}, l_{2}, l_{3}, \ldots, l_{6}$ are the lower and upper specification limit of the responses, the power $w_{1}, w_{2}, w_{3}, \ldots, w_{6}$ correspond to the weighted factor, and it is the parameter that determines the shape of $d_{1}, d_{2}, d_{3}, \ldots, d_{n}$. $c$ is a multiplier that was used to have the result obtained have normal values in the equations. To find $\mathrm{n}$ factors' values, the value of each response value is expressed as $y_{1}, y_{2}, y_{3}, \ldots, y_{6}$. The following developed equations have been used as objective functions with the constraints to determine the competitiveness indexes of a country's healthcare systems.
$\operatorname{Maximize} \sum_{i, j} \sum_{y} \operatorname{GHCI}_{i j}^{y}$

Minimize $\sum_{i, j} \sum_{y} \mathrm{HE}_{i j}^{y}$

\section{Subject to}

$\sum_{i, j, y} x_{i j}^{y} \beta_{i} \geq \sum_{i, j, y} \frac{l_{i j}^{y}}{n_{y}}$

$\sum_{i, j, y} x_{i j}^{y} \beta_{i} \leq \sum_{i, j, y} \frac{u_{i j}^{y}}{n_{y}}$

$x_{i j} \geq 0$

\section{Results and Discussion}

In this part, as a result of statistical analysis, finding the best solution and the results obtained in optimization models have been discussed. Furthermore, calculating the GHCI values of the countries considered, the advancement levels of the health systems of these countries have been ranked.

\subsection{Data Analysis and Results}

This section provides general information about the collected data for statistical analysis and shows the accuracy of the analysis. The precision of the factors with the effects was measured on the response's variables. Decision variables named as independent factors were abbreviated as gross domestic product, GDP; gross domestic product per capita, GDP PC; life expectancy, LE; the number of beds, $B$; the number of nurses and midwives, $\mathrm{NW}$; and the number of physicians, MD. The statistical analysis of factors and 
response variables are illustrated in Table 2. The results of statistical analysis showed that the accuracy of the collected values had high values of $R^{2}$. The accuracy of the statistical analysis of this study was estimated as $99.68 \%$ of the $R^{2}$ value and $99.63 \%$ of the adjusted $R^{2}$ value.

The effects of the determined factors on the GHCI were examined based on HEs. The importance of a factor on the response depends on the $P$-value of the factor as a result of the statistical analysis. Contribution ratios were calculated as percentage of contributions to the total sequential sum of squares of each source in Table 2. Higher percentages of contributions rates indicated that it calculated more variation on the responses.

The most important factor was found as GDP PC by country in the statistical analysis. ( $P$-value of GDP PC was computed as zero.) GDP, the numbers of nurses, physicians, and beds were found to be more impressive factors on HEs and GHCI. However, these results indicated that GHCI were not influenced by the HEs of countries. Thus, this factor was excluded in the application optimization model to calculate optimum values of remained factors, which was defined as an objective function. Note that the effects of factors considered for GHCI were measured as non-interactively.

\subsection{Calculation of Optimum and Feasible Values}

Optimization mathematical models for optimizing both the factors and the objective functions (or response) were developed to compute the optimal and feasible values. These values show the necessary data to compete for a country in the field of healthcare. Considering the factors analyzed, the calculated values were higher than the mean of the data of 53 countries. As a result of the statistical analysis revealed, sixth of the important factors discussed was more effective on HEs and GHCI in this study. Figure 1 shows the variation in the optimum and feasible results obtained for GHCI and HEs according to $D^{*}$. The optimum point was located between 0.52 and 0.68 of $D^{*}$ (with the creation of graphic for feasible solutions, the $D$ value was calculated as 0.72 maximum and the minimum value as 0.40 , respectively) shown in Fig. 2. The optimal point located to be within the feasible region, but two different objective functions (for different directions: max-min) ensure that the solution was nonlinear.

The objective functions and the factors constituting the constraints that have optimum and feasible values are demonstrated in Table 3. The ten feasible (one of them was optimum) results were calculated for factors and objective functions. The average of 10-D values was calculated as approximately 0.602 . The maximum level and the minimum level of $D$ values were computed as $0.65,0.5548$, respectively. The mean values for the feasible ten values of the decision variables were calculated as $\$ 796,995$ million for GDP, $\$ 47,402$ for GDP PC, 79.77 for LE, 9.18 (per 1000) for B, 4.95 (per 1000) for MD, and 10.66 for MW, separately. The results of the objective functions were calculated as mean values of 3.47 for GHCI and $9.84 \%$ of GDP for HE. By examining the optimum values of the factors, it was necessary that the budget rate should be used for minimizing the HEs and maximizing GHCI of the selected countries to measure the power of competitiveness in terms of healthcare systems.

Since the objective functions of the developed optimization model are twofold, while the factors get maximum value according to one goal function, the factors are forced to the minimum value according to the other objective function. The optimum values of the factors and objective functions take value according to this optimization structure. According to Table 3, in terms of the values of maximum GHCI and minimum HE, factors were calculated as 776.77 for GDP, 44.960 for GDP PC, 80.16 for LE, 7.62 for B, 4.77 for MD, and 13.24 for MW, respectively. The optimum values of the factors in the infrastructure of the healthcare systems were considered, and the number of medical doctors, nurses and
Table 2 Statistical results of the dependent and independent variables

\begin{tabular}{llclll}
\hline Category & Decision variables & Contribution $(\%)$ & $95 \%$ CI & $P$-value & Status \\
\hline Economical & GDP PC & 4.98 & $(-0.011575 ;-0.011412)$ & $0.0000^{*}$ & Significant \\
Economical & GDP & 17.20 & $(0.000037 ; 0.000037)$ & $0.0001^{*}$ & Significant \\
Structural & LE & 32.23 & $(0.040874 ; 0.041548)$ & $0.0001^{*}$ & Significant \\
Structural & B & 2.34 & $(-0.018633 ;-0.017805)$ & $0.0001^{*}$ & Significant \\
Structural & MD & 7.54 & $(0.009801 ; 0.011563)$ & $0.0001^{*}$ & Significant \\
Structural & NW & 35.69 & $(0.055349 ; 0.056119)$ & $0.0001^{*}$ & Significant \\
\hline
\end{tabular}

To determine the individual effects of the factors that could affect the response and $*$ Statistically significant $(P$-value $<0.01), * *$ At the margin of statistical provisionally significance $(P$-value $<0.1)$

Contribution: displays the percentage that each source contributes to the total variation in the response

CI: Confidence Interval is an interval estimation type for the actual values of an unknown population parameter calculated from the statistics of the observed data

$P$-Value: The $P$-value is a probability that measures the evidence against the null hypothesis 
Fig. 2 Optimal point according to $D^{*}, \mathrm{GHCI}$, and $\mathrm{HE}$

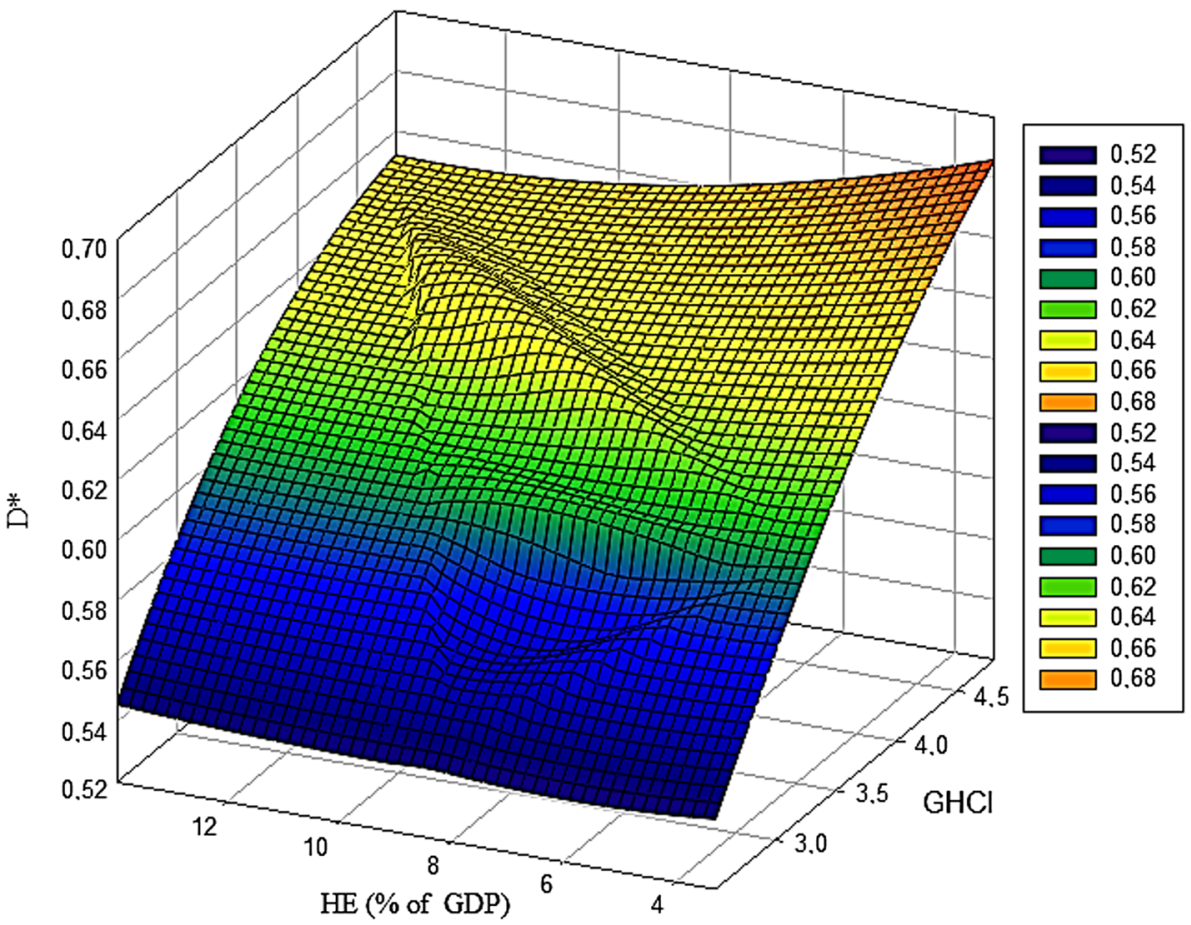

Table 3 Optimum and feasible values of GHCI and HEs

\begin{tabular}{|c|c|c|c|c|c|c|c|c|c|}
\hline \multirow{2}{*}{$\begin{array}{l}\text { Optimality } \\
\text { setting } D^{*}\end{array}$} & \multicolumn{6}{|c|}{ Decision Variables } & \multicolumn{2}{|c|}{ Objective Functions } & \multirow[t]{2}{*}{ Status } \\
\hline & GDP (Billion \$) & GDP PC & LE & $B($ per 1000$)$ & MD (per 1000) & NW (per 1000) & GHCI score & HEs ( $\%$ of GDP) & \\
\hline 0.6520 & $\$ 776.77$ & $\$ 44,960$ & 80.16 & 7.62 & 4.77 & 13.24 & 4.8155 & 13.96 & Optimum \\
\hline 0.6481 & $\$ 751.42$ & $\$ 46,910$ & 81.28 & 8.66 & 6.26 & 12.52 & 4.4967 & 13.14 & Feasible \\
\hline 0.6433 & $\$ 548.58$ & $\$ 35,200$ & 80.91 & 10.04 & 5.13 & 10.83 & 4.0470 & 11.91 & Feasible \\
\hline 0.6127 & $\$ 777.76$ & $\$ 45,940$ & 81.29 & 6.77 & 4.84 & 8.90 & 3.5266 & 10.65 & Feasible \\
\hline 0.6034 & $\$ 751.42$ & $\$ 46,910$ & 76.40 & 7.29 & 5.13 & 12.28 & 3.2886 & 3.29 & Feasible \\
\hline 0.6006 & $\$ 877.18$ & $\$ 45,940$ & 79.78 & 10.04 & 4.55 & 9.63 & 3.2478 & 9.94 & Feasible \\
\hline 0.5917 & $\$ 776.78$ & $\$ 45,940$ & 81.28 & 10.90 & 5.42 & 8.90 & 3.1211 & 9.67 & Feasible \\
\hline 0.5710 & $\$ 954.26$ & $\$ 51,800$ & 76.78 & 7.63 & 4.84 & 10.59 & 2.8988 & 9.05 & Feasible \\
\hline 0.5548 & $\$ 878.20$ & $\$ 55,700$ & 79.79 & 10.04 & 4.54 & 9.62 & 2.6377 & 8.47 & Feasible \\
\hline 0.5503 & $\$ 878.19$ & $\$ 54,720$ & 79.99 & 12.80 & 4.04 & 10.11 & 2.5886 & 8.36 & Feasible \\
\hline
\end{tabular}

midwives, and beds were found to be striking in terms of affecting the healthcare systems of countries. According to the results, an increase of $38.15 \%$ for the number of nurses and midwives (the average number of nurses and midwives was 7.5930 per 1000 people) and $41.18 \%$ for the number of beds (the average number of beds was 4.2850 per 1000 people) were required for a country's healthcare system to improve the quality of health service. In the same manner, countries need to employ $42.75 \%$ more for doctors. (The average number of medical doctors was 2.9350 per 1000 people.)

The values that each factor takes outside of optimum values were seen to affect the objective function either in the positive or negative direction. According to Table 4, as GDP
PC values of the factors increase, the value of the objective functions defined GHCI and HE decrease. This had a negative effect on GHCI, while it had a positive effect on HEs. The bidirectional tendency in the objective functions leaded to the transformation of the developed optimization models into nonlinear mathematical equations. On the reverse side, the values of GDP increase among the factors, the value of the objective function assigned GHCI increases and the value of the objective function assigned $\mathrm{HE}$ decreases. We could mention GDP and GDP PC are bidirectional tendency for the healthcare system of the country with the increase in life expectancy values as well as bidirectional effects on the healthcare system of a country. In terms of the resources, healthcare had different situations for GHCI and HEs. The 
Table 4 Trends of objective functions values according to factor values

\begin{tabular}{|c|c|c|c|c|c|c|c|c|c|}
\hline \multirow{2}{*}{$\begin{array}{l}\text { Decision vari- } \\
\text { ables }\end{array}$} & \multirow[t]{2}{*}{ Situations } & \multirow{2}{*}{$\begin{array}{l}\text { Direction of } \\
\text { values }\end{array}$} & \multicolumn{3}{|l|}{ HEs } & \multicolumn{3}{|l|}{ GHCI } & \multirow[t]{2}{*}{$D^{*}$} \\
\hline & & & Trend & Desired & Effect & Trend & Desired & Effect & \\
\hline GDP PC & $\begin{array}{l}\text { S1 } \\
\text { S2 }\end{array}$ & $\begin{array}{l}\text { Upward } \\
\text { Downward }\end{array}$ & $\begin{array}{l}\text { Downward } \\
\text { Upward }\end{array}$ & Downward & $\begin{array}{l}\text { Positive } \\
\text { Negative }\end{array}$ & $\begin{array}{l}\text { Downward } \\
\text { Upward }\end{array}$ & Upward & $\begin{array}{l}\text { Negative } \\
\text { Positive }\end{array}$ & $\begin{array}{l}\text { Positive-Constant } \\
\text { Constant-Negative }\end{array}$ \\
\hline GDP & $\begin{array}{l}\text { S1 } \\
\text { S2 }\end{array}$ & $\begin{array}{l}\text { Upward } \\
\text { Downward }\end{array}$ & $\begin{array}{l}\text { Upward } \\
\text { Downward }\end{array}$ & Downward & $\begin{array}{l}\text { Negative } \\
\text { Positive }\end{array}$ & $\begin{array}{l}\text { Upward } \\
\text { Downward }\end{array}$ & Upward & $\begin{array}{l}\text { Positive } \\
\text { Negative }\end{array}$ & $\begin{array}{l}\text { Negative-Constant } \\
\text { Constant-Positive }\end{array}$ \\
\hline LE & $\begin{array}{l}\text { S1 } \\
\text { S2 }\end{array}$ & $\begin{array}{l}\text { Upward } \\
\text { Downward }\end{array}$ & $\begin{array}{l}\text { Upward } \\
\text { Downward }\end{array}$ & Downward & $\begin{array}{l}\text { Negative } \\
\text { Positive }\end{array}$ & $\begin{array}{l}\text { Upward } \\
\text { Downward }\end{array}$ & Upward & $\begin{array}{l}\text { Positive } \\
\text { Negative }\end{array}$ & $\begin{array}{l}\text { Positive-Constant } \\
\text { Constant-Negative }\end{array}$ \\
\hline B & $\begin{array}{l}\text { S1 } \\
\text { S2 }\end{array}$ & $\begin{array}{l}\text { Upward } \\
\text { Downward }\end{array}$ & $\begin{array}{l}\text { Downward } \\
\text { Constant }\end{array}$ & Downward & $\begin{array}{l}\text { Negative } \\
\text { No Effect }\end{array}$ & $\begin{array}{l}\text { Downward } \\
\text { Constant }\end{array}$ & Upward & $\begin{array}{l}\text { Negative } \\
\text { No Effect }\end{array}$ & $\begin{array}{l}\text { No Effect } \\
\text { No Effect }\end{array}$ \\
\hline MD & $\begin{array}{l}\text { S1 } \\
\text { S2 }\end{array}$ & $\begin{array}{l}\text { Upward } \\
\text { Downward }\end{array}$ & $\begin{array}{l}\text { Constant } \\
\text { Constant }\end{array}$ & Downward & $\begin{array}{l}\text { No Effect } \\
\text { No Effect }\end{array}$ & $\begin{array}{l}\text { Downward } \\
\text { Upward }\end{array}$ & Upward & $\begin{array}{l}\text { No Effect } \\
\text { No Effect }\end{array}$ & $\begin{array}{l}\text { No Effect } \\
\text { No Effect }\end{array}$ \\
\hline NW & $\begin{array}{l}\mathrm{S} 1 \\
\mathrm{~S} 2\end{array}$ & $\begin{array}{l}\text { Upward } \\
\text { Downward }\end{array}$ & $\begin{array}{l}\text { Upward } \\
\text { Downward }\end{array}$ & Downward & $\begin{array}{l}\text { Negative } \\
\text { Positive }\end{array}$ & $\begin{array}{l}\text { Upward } \\
\text { Downward }\end{array}$ & Upward & $\begin{array}{l}\text { Positive } \\
\text { Negative }\end{array}$ & $\begin{array}{l}\text { Positive-Constant } \\
\text { Constant-Negative }\end{array}$ \\
\hline
\end{tabular}

values of the rest of these sources, except NW, affect the objective functions to a certain extent. However, the numerical increase in these two resources reaching a certain number did not affect the value of GHCI and HEs as well. In addition, MD and B factors did not have any effect on the desirability function defined $D^{*}$.

The effect of the factors affecting the healthcare system on GHCI and HE is shown in Fig. 3. The calculation of the optimum values for each factor was completed by considering the $D^{*}$ value. Areas formed constitute the feasible zone for the objective functions in Fig. 3a-1. The most important point to be considered in these figures was that the factors that were effective in the healthcare system have the maximum values for the GHCI value (local maximum), forcing it to be at a minimum level (local minimum) for HE.

There are two different behaviors in order to get the optimum values of the factors. The factors desire to get the maximum value for GHCI and want to get the minimum values for $\mathrm{HE}$ based on constructed optimization models. Therefore, $D^{*}$ values were calculated from different ranges for each figure. In addition, although HE and GHCI were defined as two independent objective functions, GHCI was affected by HEs. Our findings inferred that HE should continue to improve GHCI so that GHCI can become a much better forecaster of the quality of healthcare.

\subsection{Generating the Global Healthcare Competitiveness Index}

The optimization model with statistical analysis has been developed to demonstrate the competitiveness of the healthcare systems of the countries covered in this study. Country selected rankings were made by calculating the GHCI scores of the countries with this study on healthcare. We aimed to show that a country with a high GHCI score has a quality and competitive health system. Thus, the healthcare systems with high GHCI score will have the ability to offer a better service to the patients. The GHCI scores of the countries ranged from 0 to 6 . The average of the GHCI values of the countries was calculated 2.4758. When the GHCI scores were examined, it was found that the highest value was in the USA (5.7490) and the lowest value was in Qatar (0.4301) (see Table 5). The GHCI score of many countries was below the optimum GHCI value. Only seven out of 53 countries were above the optimum GHCI value. The GHCI score of 19 countries was above the average GHCI score. The rest of these countries need to improve their GHCI scores immediately.

The results of this study partially coincide with the results obtained in several studies. The increase in HEs is caused by various factors, such as aging of the population, medical technology, and developments in living standards. In the context of the investigations, as people's quality of life and their willingness to live increases, HEs increase. In terms of the data, it is seen that HEs are high in economically developed countries further than developing countries [21]. In terms of the healthcare, policies of governments are examined, and it is desirable to reduce the HE which is a burden on the country's economy.

According to observations, it was determined that the values of HEs fluctuated from country to country. The levels of HEs were mainly calculated as high in USA, Japan, Germany, France, and UK, while HEs were estimated low particularly in Cyprus, Lithuania, Estonia, Latvia, and Croatia. Comparing different countries defined locational, we can advocate that in the European region, where there was a high number of developed countries, and the level of HEs was the highest compared to the other location. As a remarkable point, there are large differences in HEs among European countries. For instance, in the level of $\mathrm{HE}$ in Germany, France was higher than the level of $\mathrm{HE}$ in Finland and Greece. Obviously, we can conclude that 
Fig. 3 Behaviors of factors affecting GHCI and HE according to $\mathrm{D}$

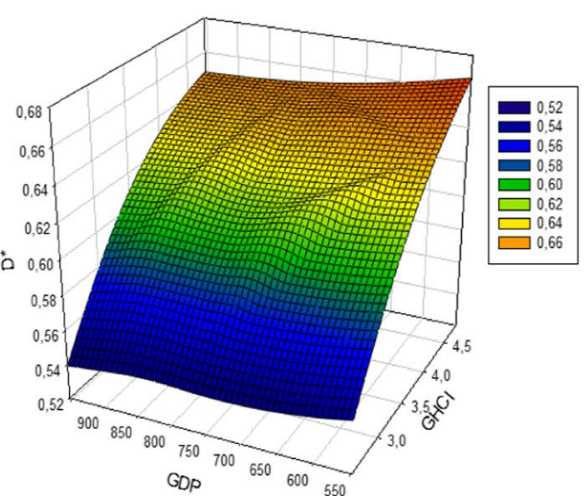

(a) Effect of GDP on GHCI according to D*

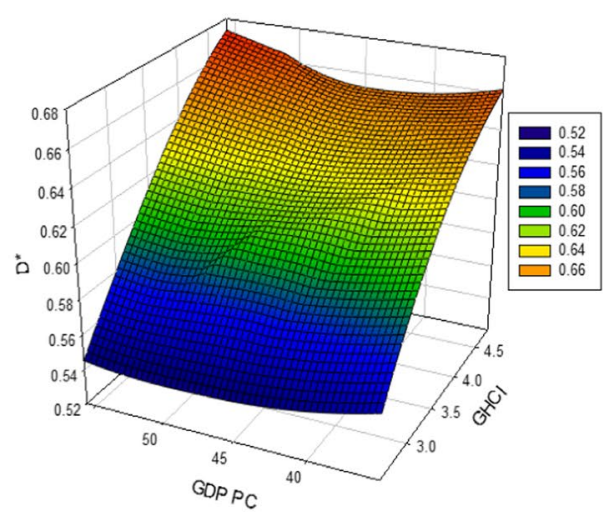

(c) Effect of GDP PC on GHCI according to D*

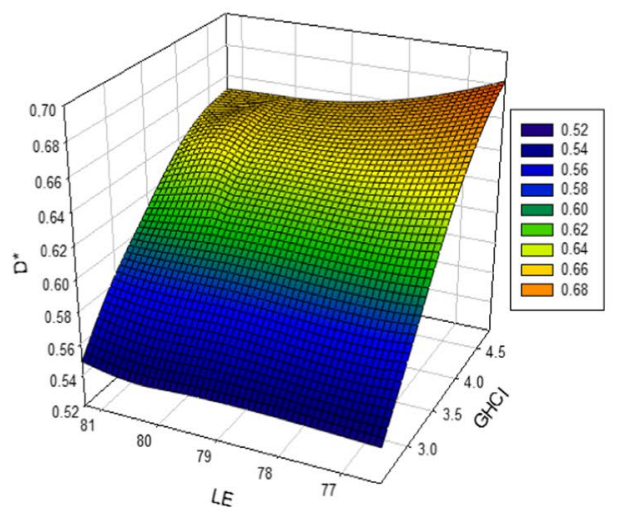

(e) Effect of LE on GHCI according to D*

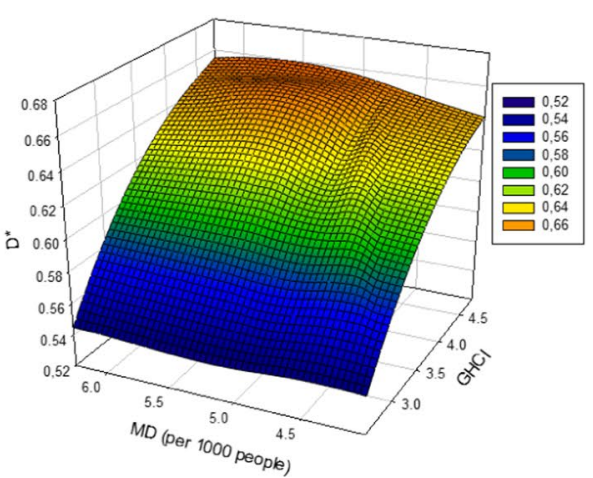

(g) Effect of MD on $\mathrm{GHCl}$ according to $\mathrm{D}^{*}$

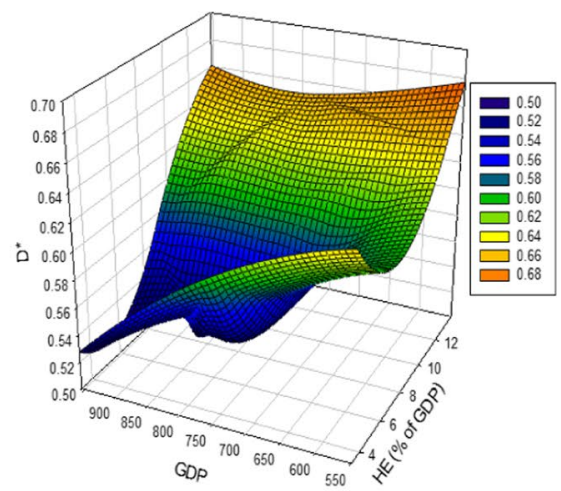

(b) Effect of GDP on HE according to D*

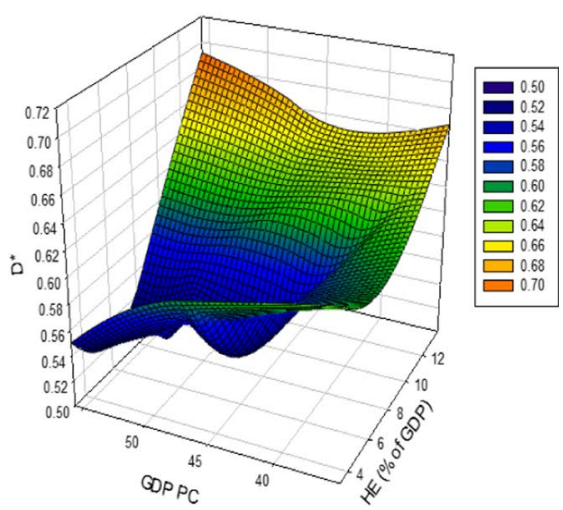

(d) Effect of GDP PC on HE according to D*

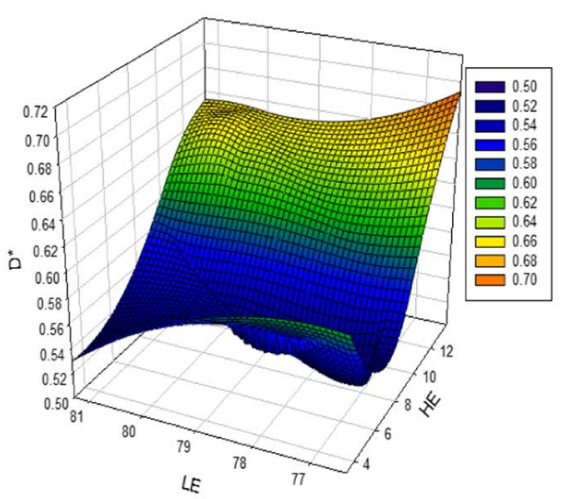

(f) Effect of LE on HE according to D*

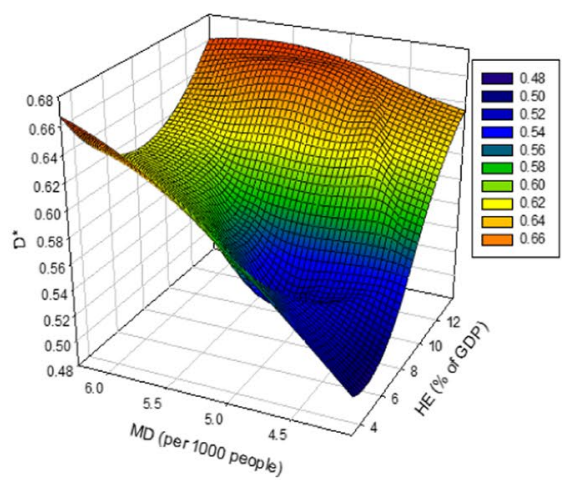

(h) Effect of MD on HE according to D* 
Fig. 3 (continued)

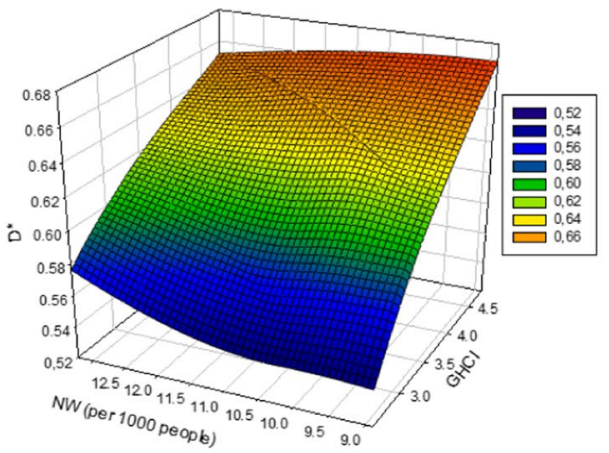

(i) Effect of NW on GHCI according to D*

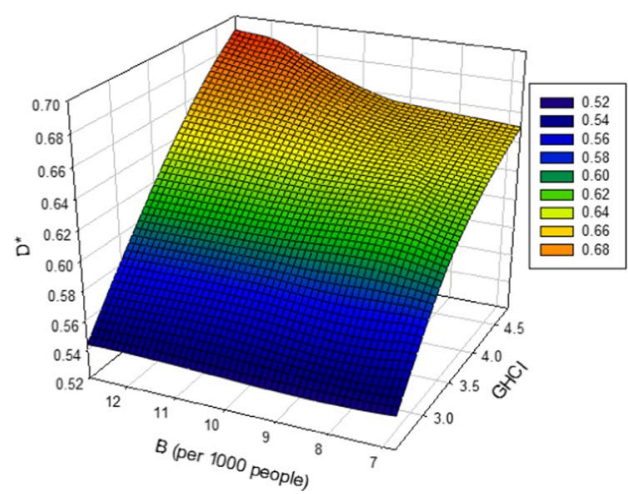

(k) Effect of B on GHCI according to D*

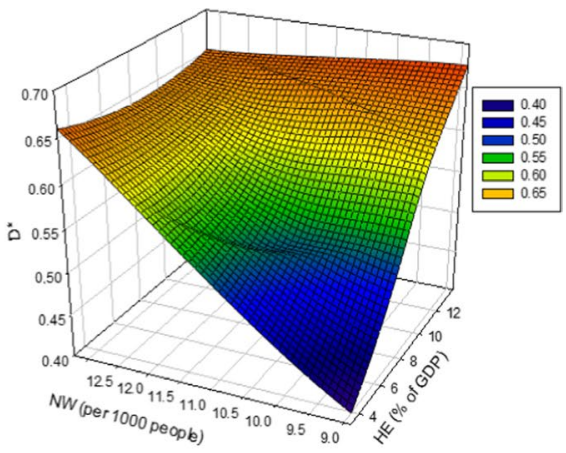

(j) Effect of NW on HE according to D*

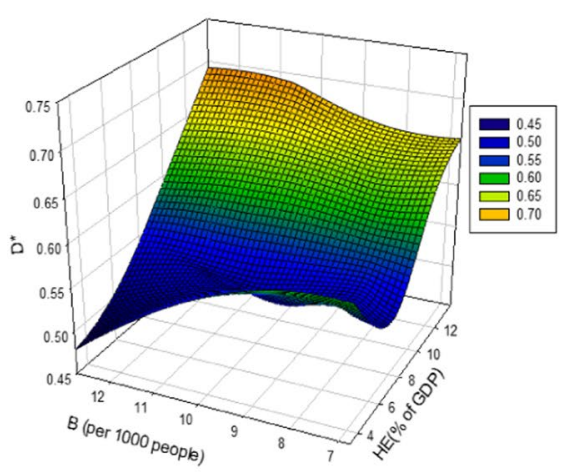

(l) Effect of B on HE according to D* there was an imbalance in the HEs of countries close to each other.

The most noteworthy factor in countries with above average GHCI value is the amount of GDP in these countries. It should be noted that the fact that the amount of the HEs is high in a country does not mean that it has a quality healthcare system. Indeed, the patient satisfaction surveys support this outcome in most of these countries. According to the government policies in these countries, it is a common idea to reduce HEs. The countries with high HEs (such as UK, Canada, Japan, Italy, Germany, France, and USA) healthcare systems are needed to be examined in detail. It is inevitable that countries with social and nonsocial healthcare systems will have an impact on HEs.

When we look at health services in a comparative way, the high proportion of elderly people from the Scandinavian countries has become a major challenge in the delivery of healthcare. Likewise, the length of waiting times due to the density of the elderly has become unacceptable for England. In this regard, there is the pressure of providing the service to be provided in the health sector to its citizens before overseas people. Despite the revised health system in the USA, there are sectoral problems due to the increasing cost of health expenditures. Although most of the citizens in the country have complementary supplementary insurance, they cannot get a comprehensive service. In this regard, in order to receive full-scale healthcare, out of the country are mostly exported from the USA. However, the USA is still at the top of the list of competitive health sectors because it maintains its position as the most advanced country in terms of private healthcare management and innovation.

\subsection{Limitations of the study}

This study has also its limitations. For example, the indices such as the number of private and public hospitals of a country were not able to be considered in this study because of lack of information about them. However, our independent variable as the number of beds or exam rooms instead of the number of hospitals was considered in the optimization models. Another limitation was about the data being relatively short-term. We recommend that we use decision variables to predict long-term global healthcare index five years and beyond.

We have taken a small step to compare several factors that may impact the GHCI. We found that two economic dimensions can be better indicators than HE even though HE is also a good predicting variable for high-quality healthcare service. We encourage for further refinement of the GHCI by including healthcare resources (types of hospitals, technicians, technology, etc.) and the components of healthcare (governments as a rule/law maker, pharmaceutics sector, healthcare insurance companies, etc.) so that it can become a more reliable index. Thus, it may be able to better predict 
Table 5 GHCI scores and ranking

\begin{tabular}{|c|c|c|c|}
\hline GDP PC Rank & Country & GHCI score & $\overline{\text { GHCI rank }}$ \\
\hline 1 & Norway & 2.7898 & 20 \\
\hline 2 & Switzerland & 3.1924 & 14 \\
\hline 3 & Luxembourg & 1.5952 & 44 \\
\hline 4 & Qatar & 0.4301 & 53 \\
\hline 5 & Iceland & 4.4213 & 2 \\
\hline 6 & Denmark & 3.9482 & 4 \\
\hline 7 & United States & 5.7490 & 1 \\
\hline 8 & Sweden & 3.0716 & 16 \\
\hline 9 & Australia & 3.2530 & 12 \\
\hline 10 & Ireland & 2.9237 & 19 \\
\hline 11 & Singapore & 1.6990 & 41 \\
\hline 12 & Netherlands & 2.2770 & 28 \\
\hline 13 & Austria & 2.0458 & 33 \\
\hline 14 & Finland & 3.9013 & 5 \\
\hline 15 & Germany & 4.1543 & 3 \\
\hline 16 & Canada & 3.1059 & 15 \\
\hline 17 & Hong Kong & 2.3264 & 26 \\
\hline 18 & United Kingdom & 2.7565 & 21 \\
\hline 19 & Belgium & 2.5766 & 22 \\
\hline 20 & Kuwait & 0.7624 & 52 \\
\hline 21 & United Arab Emirates & 0.9038 & 50 \\
\hline 22 & New Zealand & 3.5627 & 8 \\
\hline 23 & France & 3.7094 & 7 \\
\hline 24 & Brunei & 2.0590 & 32 \\
\hline 25 & Japan & 3.8495 & 6 \\
\hline 26 & Israel & 2.2127 & 30 \\
\hline 27 & Italy & 3.2989 & 11 \\
\hline 28 & Korea, Rep. & 2.2436 & 29 \\
\hline 29 & Spain & 2.9715 & 18 \\
\hline 30 & Malta & 3.3308 & 10 \\
\hline 31 & Cyprus & 1.9913 & 36 \\
\hline 32 & Saudi Arabia & 1.5846 & 45 \\
\hline 33 & Slovenia & 3.3988 & 9 \\
\hline 34 & Bahrain & 1.2660 & 48 \\
\hline 35 & Bahamas & 1.4255 & 47 \\
\hline 36 & Portugal & 3.2320 & 13 \\
\hline 37 & Greece & 2,3719 & 24 \\
\hline 38 & Oman & 1.6950 & 42 \\
\hline 39 & Estonia & 2.0606 & 31 \\
\hline 40 & Czech Republic & 2.9956 & 17 \\
\hline 42 & Trinidad \& Tobago & 0.8689 & 51 \\
\hline 43 & Uruguay & 2.3718 & 25 \\
\hline 44 & Lithuania & 1.9727 & 38 \\
\hline 45 & Latvia & 1.5170 & 46 \\
\hline 46 & Chile & 1.9958 & 35 \\
\hline 47 & Poland & 2.3067 & 27 \\
\hline 48 & Hungary & 2.0242 & 34 \\
\hline 49 & Panama & 1.7983 & 40 \\
\hline 50 & Croatia & 2.4418 & 23 \\
\hline 51 & Argentina & 1.2556 & 49 \\
\hline
\end{tabular}

Table 5 (continued)

\begin{tabular}{llll}
\hline GDP PC Rank & Country & GHCI score & GHCI rank \\
\hline 52 & Turkey & 1.6534 & 43 \\
53 & Costa Rica & 1.8840 & 39 \\
\hline
\end{tabular}

future GHCI. Since there are limited studies on this subject (being the first study on this subject), this study is very important for future studies in order to calculate the index of healthcare systems for cities or countries.

\section{Conclusion}

Healthcare dates back ancient times depending on the development of the world and humanity. Applications of the politics in terms of health system have been determined, and adapting it to the changing world scheme, the process of drawing up different approaches for each term have been considered in a methodology in relation to the approaches of national and international elements affecting that period. The rise in the cost and expenditure of healthcare during this process is now determined by many variables, on the one hand, with the use of high technology to provide healthcare, the existence of expensive treatment methods in the form of supply, on the other hand, rise in income, improvements in the living standards, demographic changes, etc., in the form of demand. The existence of these items necessitates the application of changes. When health sector is considered socioeconomically, the main reason why developments in health sector should be mostly financed: a) by public sector and b) by private sector is regarded as a problem to be dealt with is related to finance and carrying out this organization. As the Corona Virus (Covid-19), which emerged in Chine and spread around the world, bringing out global health and economic problems along with, the importance of public sector has once been shown to be highly important in the field of healthcare. As a consequence, it is necessary that public should carry out an effective and leading service regarding the evaluation of health system and healthcare because the most important reason of this situation is the conversion of a health system, which has a social structure, to a nonsocial structure.

The basis of this study was to develop optimization models to use the healthcare economics of the countries more efficiently. In these models, the constraints were derived from the factors that affect the healthcare economics besides healthcare systems. Thus, the optimum and feasible values of the factors as well as the GHCI and HE data were calculated in this study. According to the results of the study, we proved that allocating too much HE budgets (that can be regarded as waste) does not guarantee to have a high-quality healthcare 
system in a country. Index of healthcare competitiveness shows how good the quality service is in the healthcare field of countries. This index determines the ease or difficulty of receiving services of patients from hospitals or other health institutions. Taking the results obtained into consideration in this paper, the competitiveness of a country's healthcare system will only be possible if it carries optimum or feasible values. We have concluded that countries under these values have low quality of healthcare systems.

\section{Compliance with ethical standards}

Conflict of interest The authors declare that they have no conflict of interest.

\section{References}

1. Gowen, C.R.; McFadden, K.L.; Tallon, W.J.: On the centrality of strategic human resource management for healthcare quality results and competitive advantage. J. Manag. Dev. 25(8), 806-826 (2006)

2. Sik-Lanyi, C.; Orbán-Mihálykó, É.: Accessibility testing of european health-related websites. Arab. J. Sci. Eng. 44(11), 9171$9190(2019)$

3. Johnson, M.; Burgess, N.; Sethi, S.: Temporal pacing of outcomes for improving patient flow: design science research in a National Health Service hospital. J. Oper. Manag. 66(1-2), 35-53 (2020)

4. Materla, T.; Cudney, E.A.: An integrated methodology for evaluating patient service quality. Total Qual. Manag. Bus. Excell. 25, 896 (2018)

5. Saha, E.; Ray, P.K.: Modelling and analysis of inventory management systems in healthcare: a review and reflections. Comput. Ind. Eng. 137, 106051 (2019)

6. Parast, M.M.; Golmohammadi, D.: Quality management in healthcare organizations: empirical evidence from the baldrige data. Int. J. Prod. Econ. 216, 133-144 (2019)

7. Mohapatra, S., Mohanty S., Mohanty, S.: Smart healthcare: an approach for ubiquitous healthcare management using IoT. In: Big data analytics for intelligent healthcare management, Elsevier, pp. 175-196 (2019)

8. Askfors, Y.; Fornstedt, H.: The clash of managerial and professional logics in public procurement: implications for innovation in the health-care sector. Scand. J. Manag. 34(1), 78-90 (2018)

9. Peixoto, H.; Duarte, J.; Abelha, A.; Santos, M.; Machado, J.: ScheduleIT-open-source preventive actions management plataform in healthcare information systems. Procedia Technol. 5, 734-742 (2012)

10. Kirkman-Liff, B.L.; Huijsman, R.; Van Der Grinten, T.; Brink, G.: Hospital adaptation to risk-bearing: managerial implications of changes in purchaser-provider contracting. Health Policy (New York) 39(3), 207-223 (1997)

11. Andritsos, D.A.; Tang, C.S.: Introducing competition in healthcare services: the role of private care and increased patient mobility. Eur. J. Oper. Res. 234(3), 898-909 (2014)
12. Ben-Romdhane, M.; Maalej, A.; Tlili, M.; Rebai, C.; Rivet, F.; Dallet, D.: Event-driven ECG sensor in healthcare devices for data transfer optimization. Arab. J. Sci. Eng. 56, 896 (2020)

13. Vissers, J., Adan, I.: Service philosophies for hospital admission planning. In: Health Operations Management: Patient Flow Logistics in Health Care, Routledge, pp. 264-281 (2005).

14. Manning, W.G.: Modeling Cost and Expenditure for Healthcare. In: Culyer, A.J. (ed.) Encyclopedia of Health Economics, pp. 299-305. Elsevier, San Diego (2014)

15. Dehlendorff, C.; Kulahci, M.; Andersen, K.K.: Designing simulation experiments with controllable and uncontrollable factors for applications in healthcare. J. R. Stat. Soc. Ser. C 60(1), 31-49 (2010)

16. Xia, R.; Liang, T.; Zhang, Y.; Wu, S.: Is global competitive index a good standard to measure economic growth? A suggestion for improvement. Int. J. Serv. Stand. 66, 258 (2012)

17. Kamra, V.; Singh, H.; De Kumar, K.: Factors affecting patient satisfaction: an exploratory study for quality management in the health-care sector. Total Qual. Manag. Bus. Excell. 27(9-10), 1013-1027 (2016)

18. Xie, Z.; Or, C.: Associations between waiting times, service times, and patient satisfaction in an endocrinology outpatient department: a time study and questionnaire survey. Inq. J. Heal. Care Organ. Provision, Financ. 54, 1-10 (2017)

19. Marsh, K.; Lanitis, T.; Neasham, D.; Orfanos, P.; Caro, J.: Assessing the value of healthcare interventions using multi-criteria decision analysis: a review of the literature. Pharmacoeconomics 32(4), 345-365 (2014)

20. ArunKumar, G.; Dillibabu, R.: Design and application of new quality improvement model: kano lean six sigma for software maintenance project. Arab. J. Sci. Eng. 41(3), 997-1014 (2016)

21. Jaba, E.; Balan, C.B.; Robu, I.-B.: The relationship between life expectancy at birth and health expenditures estimated by a crosscountry and time-series analysis. Procedia Econ. Financ. 56, 89 (2014)

22. Rowe, A.K.; de Savigny, D.; Lanata, C.F.; Victora, C.G.: How can we achieve and maintain high-quality performance of health workers in low-resource settings? Lancet 366(9490), 1026-1035 (2005)

23. Reiling, J.: Safe design of healthcare facilities. Qual. Saf. Heal. Care 15, i34-i40 (2006)

24. OECD: OECD Data Health Care Resources 2015. (2017).

25. Farahani, M.; et al.: Impact of health system inputs on health outcome: a multilevel longitudinal analysis of Botswana national antiretroviral program (2002-2013). PLoS One 26, 94 (2016)

26. World Population Review: Life Expectancy by Country 2017. (2017).

27. Anand, S.; Ravallion, M.: Human development in poor countries: on the role of private incomes and public services. J. Econ. Perspect. 7(1), 133-150 (1993)

28. OECD: OECD Data Health Expenditure (Percent of GDP). (2016).

29. World Bank: World Health Organization Global Health Expenditure database. Health expenditure, total (\% of GDP). (2014).

30. Wu, F.-C.: Optimization of correlated multiple quality characteristics using desirability function. Qual. Eng. 17(1), 119-126 (2004) 